\title{
Investigating the Molecular Genetic Basis of Cytoplasmic Sex Determination Caused by Wolbachia Endosymbionts in Terrestrial Isopods
}

\author{
Myriam Badawi ${ }^{\circledR}$, Bouziane Moumen, Isabelle Giraud, Pierre Grève and Richard Cordaux * \\ Laboratoire Ecologie et Biologie des Interactions, Equipe Ecologie Evolution Symbiose, Université de Poitiers, \\ UMR CNRS 7267, Bât. B8, 5 rue Albert Turpin, TSA 51106, 86073 Poitiers CEDEX 9, France; \\ Myriam.Badawi@univ-lemans.fr (M.B.); bouziane.moumen@univ-poitiers.fr (B.M.); \\ isabelle.giraud@univ-poitiers.fr (I.G.); pierre.greve@univ-poitiers.fr (P.G.) \\ * Correspondence: richard.cordaux@univ-poitiers.fr; Tel.: +33-5-49-45-36-51
}

Received: 29 March 2018; Accepted: 5 June 2018; Published: 8 June 2018

\begin{abstract}
In animals, sexual differences between males and females are usually determined by sex chromosomes. Alternatively, sex may also be determined by vertically transmitted intracellular microbial endosymbionts. The best known cytoplasmic sex manipulative endosymbiont is Wolbachia which can, for instance, feminize genetic males into phenotypic females in the terrestrial isopod Armadillidium vulgare. However, the molecular genetic basis of cytoplasmic sex determination is unknown. To identify candidate genes of feminization induced by Wolbachia strain $w$ VulC from A. vulgare, we sequenced the genome of Wolbachia strain wCon from Cylisticus convexus, the most closely related known Wolbachia strain to $w \mathrm{VulC}$ that does not induce feminization, and compared it to the $w \mathrm{VulC}$ genome. Then, we performed gene expression profiling of the 216 resulting $w \mathrm{VulC}$ candidate genes throughout host developmental stages in $A$. vulgare and the heterologous host C. convexus. We identified a set of 35 feminization candidate genes showing differential expression during host sexual development. Interestingly, 27 of the 35 genes are present in the $f$ element, which is a piece of a feminizing Wolbachia genome horizontally transferred into the nuclear genome of A. vulgare and involved in female sex determination. Assuming that the molecular genetic basis of feminization by Wolbachia and the $f$ element is the same, the 27 genes are candidates for acting as master sex determination genes in A. vulgare females carrying the $f$ element.
\end{abstract}

Keywords: cytoplasmic sex factor; feminization; sexual development; genome sequencing; gene expression profile; Wolbachia; terrestrial isopods

\section{Introduction}

Sex determination is a key biological pathway which governs the sexual differentiation of an individual into a male or female and its ability to produce male or female gametes. Although development as either a male or female is a generally conserved feature in animals, there is an amazing diversity of modes of sex determination [1,2]. The most common mode of sex determination is genotypic sex determination, in which nuclear genetic elements control sex determination. Prime examples of genotypic sex determination are sex chromosomes, i.e., chromosomes that carry sex-determining factors. Sex chromosome systems can take two major forms: male heterogamety (when males are heterozygous for the sex chromosomes and females homozygous, called XY systems), and female heterogamety (when females are heterozygous for the sex chromosomes and males homozygous, called ZW systems). The second mode of sex determination is environmental sex determination, in which external stimuli control sex determination. Environmental sex determination is defined here in 
a very broad sense, meaning any factor that is not nuclear, be it abiotic or biotic, and can trigger male or female differentiation from a single nuclear genotype. Examples of non-nuclear triggers include temperature, photoperiod, social ties and parasites, among others.

Among parasites, several intracellular microorganisms have evolved the ability to feminize their hosts, a phenomenon known as cytoplasmic sex determination [3-5]. Disrupting the mode of sex determination of their hosts in favor of females may be advantageous for such inherited endosymbionts because they are predominantly transmitted vertically through female egg cytoplasm, not male sperm. Thus, males represent dead ends for these microorganisms. Consequently, any effect of the endosymbionts that distort host sex ratio towards females will be selectively advantageous for the endosymbionts, provided that the sex ratio distortion does not unduly affect the ability of hosts to reproduce. The best known causative agent of cytoplasmic sex determination is the $\alpha$-proteobacterium Wolbachia, which has attracted considerable interest, notably for its wide range of hosts and induced phenotypes [6,7]. In particular, several Wolbachia strains have been shown to cause feminization of genetic males into phenotypic females $[3,4,8]$. Feminization has been reported in some insects $[9,10]$ but is most widespread in terrestrial isopod crustaceans, including the common pillbug Armadillidium vulgare [11-13].

A. vulgare has a female heterogametic system of sex chromosomes $(\mathrm{ZZ} / \mathrm{ZW})$ [14]. In this context, inherited Wolbachia endosymbionts lead to the feminization of ZZ genetic males that develop into fully functional females during sexual differentiation [4,8,11,12]. As Wolbachia invades the population, it leads to the disappearance of heterogametic females (ZW) and therefore, to $\mathrm{W}$ sex chromosome extinction. Effectively, this means that the female sex-determining factor shifts from nuclear (W sex chromosome) to cytoplasmic (Wolbachia) localization [15]. Interestingly, Wolbachia horizontally transferred its genome into the host nucleus, in a genomic region associated with female sex-determination called the $f$ element [16]. The $f$ element ultimately led to the birth of a new W sex chromosome [16]. Thus, Wolbachia is not only a factor inducing cytoplasmic sex determination, it also has the potential to act as a substantial evolutionary force that can trigger turnovers of sex chromosomes in A. vulgare. However, the mechanisms and genes responsible for feminization by Wolbachia and the $f$ element are unknown [15].

In general, the molecular mechanisms underlying Wolbachia-host interactions remain poorly known (reviewed in [17]). This is largely due to the fact that Wolbachia is an unculturable bacterium with an obligate intracellular lifestyle. With respect to feminization, genome sequencing of the feminizing Wolbachia strain $w \mathrm{VulC}$ identified many genes that could potentially interact with its host $A$. vulgare, especially genes that encode for proteins containing eukaryotic-like domains (at least 83 putative genes including 75 with ankyrin domain; Figure S1). These domains are commonly found in eukaryotic proteins and are relatively rare in bacteria, but particularly abundant in Wolbachia genomes [18]. Genes containing eukaryotic-like domains are particularly enriched in prophage WO, which is present in many Wolbachia genomes, sometimes in multiple copies [19-21]. These genes are of particular interest as their role in host-pathogen interactions has been demonstrated in other microorganisms such as Legionella pneumophila [22,23], Coxiella burnetii [22,24] and Anaplasma phagocytophilum [25]. In Wolbachia, it has already been shown that some of these genes show sex-specific expression [26] or are correlated to the induced phenotype [27-29]. In several Wolbachia strains that infect terrestrial isopods, the ankyrin gene $p k 2 b 2$ (embedded in one of the 7 prophage regions of the $w$ VulC genome; Figure S1) is only expressed in females from species infected by feminizing strains [30]. Sequencing of the $w$ VulC genome also revealed the presence of numerous export and secretion systems such as T4SS, T1SS, Sec, Tat, Lol and Bam, through which effectors may transit towards host cytoplasm. This result is consistent with earlier reports, indicating that the presence of such systems is a general feature of Wolbachia endosymbionts [31-33]. In $w$ VulC, the T4SS has been well studied [31,34]; however, no effector or molecular mechanism of feminization induced by Wolbachia has been uncovered to date. This is in contrast with cytoplasmic incompatibility (CI), the most common phenotype induced by Wolbachia, which has recently been shown to involve the pair of genes, cifA and cifB [35-37]. 
So far, many studies aiming at identifying candidate genes involved in Wolbachia-host interactions used targeted approaches, i.e., by focusing on genes containing functional domains with prior knowledge of involvement in molecular interactions. Considering the quite limited amount of functional knowledge of Wolbachia genes (e.g., $23 \%$ of hypothetical genes in $w \mathrm{VulC}$ genome), it may be relevant to consider alternative strategies to identify candidate effectors to elucidate molecular mechanisms of induced phenotypes [38]. In this study, we used a combination of comparative genomics and expression profiles throughout host development to identify candidate genes of feminization induced by Wolbachia $w \mathrm{VulC}$, without prior functional knowledge of genes. Specifically, we sequenced the genome of Wolbachia wCon from the terrestrial isopod Cylisticus convexus and compared it to the $w$ VulC genome. $w$ Con was selected because it is the most closely related known strain to $w$ VulC available in our laboratory that does not induce feminization (but CI) $[39,40]$. In addition, it has been shown that $w \mathrm{VulC}$ also induces feminization when transfected into $C$. convexus and $w$ Con also induces CI when transfected into A. vulgare [39,41], indicating that the observed phenotypes are related to the Wolbachia strains. Next, we performed gene expression profiling of selected $w$ VulC genes throughout host developmental stages in $w \mathrm{VulC}$ native host $A$. vulgare and following $w \mathrm{VulC}$ transfection in a heterologous host (C. convexus). C. convexus was selected for comparison with $A$. vulgare because: (i) $w \mathrm{VulC}$ has been shown to induce feminization after transfection in C. convexus, and (ii) A. vulgare and C. convexus differ in their timing of sexual differentiation [41]. Using this strategy, we identified a set of 35 candidate genes out of the $1888 w$ VulC genes that may be implicated in feminization induced by Wolbachia $w \mathrm{VulC}$ in the host $A$. vulgare, two of which appear to be particularly promising.

\section{Materials and Methods}

\subsection{Terrestrial Isopod Lines}

All C. convexus individuals naturally infected with Wolbachia strain $w$ Con were from our laboratory line CCw, derived from individuals caught in Avanton, France, in 2004. All C. convexus individuals carrying Wolbachia strain $w \mathrm{VulC}$ were from our laboratory line AW (derived from individuals caught in Villedaigne, France, in 1997) and were experimentally infected with Wolbachia strain $w$ VulC (from our laboratory line ZN, derived from individuals caught in Celles sur Belle, France, 1991), as described in Badawi et al. [41]. All A. vulgare individuals naturally infected with Wolbachia strain $w$ VulC were from our laboratory line $\mathrm{ZN}$. Isopods were reared at $20^{\circ} \mathrm{C}$ with food ad libitum (dead lime tree leaves and carrots) under a natural photoperiod, except those in cross-breeding and juveniles which were reared under a 18L:6D photoperiod.

\section{2. wCon DNA Enrichment and Genome Sequencing}

To identify the C. convexus tissue naturally possessing the highest Wolbachia wCon density, DNA was extracted from ovaries, the nervous chain and the hemolymph of four $C$. convexus females using a standard phenol/chloroform extraction [42]. Proportions of $w$ Con, mitochondrial and nuclear DNA were estimated with quantitative PCR targeting single copy genes wsp, cytochrome oxidase I (COI) and androgenic hormone (AH), respectively. Reactions and cycle conditions were as described in Le Clec'h et al. [43] and in Table S1. Copy numbers were estimated using calibration range curves as described in Le Clec'h et al. [43]. We assessed the ratios of the base pair number from mitochondria $\left(\mathrm{R}_{\mathrm{mt}}\right)$ and nucleus $\left(\mathrm{R}_{\mathrm{nuc}}\right)$ relative to the $w$ Con genome, as follows: $\mathrm{R}_{\mathrm{mt}}=\left(\mathrm{G}_{\mathrm{mt}} \times \mathrm{N}_{\mathrm{COI}}\right) /\left(\mathrm{G}_{\mathrm{Wo}} \times \mathrm{N}_{\mathrm{wsp}}\right)$ and $R_{\text {nuc }}=\left(G_{\text {nuc }} \times N_{A H}\right) /\left(G_{W o} \times N_{\text {wsp }}\right)$, where $G_{m t}, G_{\text {nuc }}$ and $G_{W o}$ are mitochondrial, nuclear and Wolbachia genome sizes, respectively, and $\mathrm{N}_{\mathrm{COI}}, \mathrm{N}_{\mathrm{AH}}$ and $\mathrm{N}_{\mathrm{wsp}}$ are COI, AH and wsp copy numbers, respectively. Absolute genome sizes were estimated as $1.7 \mathrm{Mb}$ and $2 \mathrm{~Gb}$ for $w \mathrm{Con}$ and nuclear genomes respectively, based on information available for the closely related Wolbachia $w \mathrm{VulC} /$ A. vulgare complex (http://www.genomesize.com/). C. convexus mitochondrial genome length is $14 \mathrm{~kb}$, based on sequencing data [44]. 
Ovaries were selected for further analyses as they contained the highest ratio of $w$ Con copies. We dissected ovaries, as well as nerve cords of 30 C. convexus sisters infected with the wCon Wolbachia strain. First, we performed PCR amplification and Sanger sequencing of the Wolbachia-specific markers wsp and ftsZ using the DNA of the nerve cords from each of the 30 females as templates and then verified that the Wolbachia strain was indeed $w$ Con (see Table S1 for primers and PCR conditions). Next, to enrich the sample in $w$ Con DNA, we homogenized the ovaries of the 30 females with a Dounce tissue grinder B within a PBS solution containing sucrose $(0.25 \mathrm{M})$ and L-glutamine $(5 \mathrm{mM})$ to crush cells while keeping nuclei intact. We then passed the solution through a $5 \mu \mathrm{m}$ filter that specifically retained nuclei but not Wolbachia. Next, the DNA of the Wolbachia-enriched solution was extracted using a standard phenol/chloroform procedure. RNA contaminants were removed with RNase A treatment $\left(0.2 \mu \mathrm{g} / \mu \mathrm{L}\right.$ at $37^{\circ} \mathrm{C}$ for $\left.1 \mathrm{~h}\right)$. Then, the sample was purified through another round of phenol/chloroform extraction. We determined the relative proportion of $w$ Con DNA relative to mitochondrial and nuclear DNA with quantitative PCR (qPCR), as described above. The DNA sample was used by GenoScreen (Lille, France) to prepare a Nextera sequencing library. The library was sequenced by GenoScreen in a 1/4 and a 1/8 454 GS FLX sequencer runs with Titanium chemistry.

Bad quality reads and mitochondrial reads were filtered out and the remaining reads were assembled de novo with gsAssembler (Newbler 2.6) with default parameters except seed step set to 1, yielding 5153 contigs. $w$ Con contigs were retrieved using BLAT (minimal identity set to 60), Mauve and R2CAT [45-47]. Six representative Wolbachia reference genomes from supergroups A and B were used to retrieve $w$ Con contigs: $w \mathrm{Mel}$ (NC_002978.6), $w$ Ri (NC_012416.1), $w$ Pip-Pel (NC_010981.1), wAlB (NZ_CAGB00000000.1), $w$ VitB (NZ_AERW00000000.1) and $w$ VulC (ALWU00000000). The assembly of 389 contigs showing high similarity with Wolbachia genomes were manually improved by exploiting the de Bruijn graph to join contigs truncated due to repeats, which resulted in a final $w$ Con assembly of 237 contigs. Gene prediction and annotation was performed with PROKKA pipeline [48] and manually curated in artemis. Clusters of Orthologous Groups of proteins (COG) were assigned to each predicted protein using BLASTp with minimal identity of $70 \%$ on at least $70 \%$ of the protein sequences. The annotated genome sequence and raw sequence data were deposited in GenBank under bioproject accession number PRJNA439208.

\subsection{In Silico Classification of wVulC Genes}

To determine a list of feminization candidate genes, all annotated genes from the $w$ VulC genome (GenBank accession number ALWU00000000) were processed using a homemade pipeline of Perl scripts (Supplementary Materials 1). First, according to genome annotation, all repeats (including transposable elements, genes coding for prophages and other repeated genes), pseudogenes (including all coding sequences of genes annotated as "pseudogenes" and small coding sequences of genes split in two chunks) and small peptides ( $<50$ amino acids) were removed. Repeats were discarded because they were not well suited for downstream expression analyses by PCR. Pseudogenes and small peptides were discarded as they are unlikely to be functional genes. Second, all genes belonging to the core genome of Wolbachia strains that infect arthropods were discarded. This core genome was computed using OrthoMCL [49] with a minimal identity of $70 \%$ and a minimal e-value of $10^{-6}$, using the following five complete Wolbachia genomes from supergroups A and B: wMel (NC_002978.6), wRi (NC_012416.1), $w$ Ha (NC_021089.1), $w$ No (NC_021084.1), $w$ Pip-Pel (NC_010981.1). Finally, all proteins from $w$ VulC showing $100 \%$ similarity with their homolog in the closely related, non-feminizing $w$ Con genome on at least $90 \%$ of their length, based on BLASTp searches, were discarded. The remaining genes were considered as candidates and were selected for expression analyses.

\subsection{Expression of wVulC Candidate Genes throughout Host Sexual Development}

To investigate the expression of Wolbachia candidate genes during host sexual development, genetic crosses involving $A$. vulgare and $C$. convexus individuals were performed between uninfected males and females carrying the $w \mathrm{VulC}$ Wolbachia strain. In the terrestrial isopods A. vulgare and 
C. convexus, embryos that inherited the feminizing Wolbachia strain $w$ VulC develop into functional females. This conversion of genetic males into functional phenotypic females occurs during host sexual differentiation. In brief, A. vulgare juvenile development occurs within a period of 10 to 15 weeks after the release of juveniles from the female ventral pouch. During this period, eight post-embryonic stages were defined, each corresponding to an intermolt stage. Gonads differentiate during stages 4 to 6 and after this period the experimental reversion of gonadal sex becomes impossible [50-52]. Therefore, Wolbachia is assumed to act before or during sexual differentiation as it inhibits male gonad differentiation and hence converts genetic males into phenotypic females. $C$. convexus has a different sexual differentiation timing compared to A. vulgare, as it shows a one-stage shift and occurs during stages 3 to 5 [41]. After hatching, juveniles were sampled individually 2-3 days after each molt, from the first molt (stage 1) to the seventh molt (stage 7), and stored in liquid nitrogen.

First, we tested whether $w$ VulC candidate genes are expressed in any of the gonadal differentiation key stages (3 to 6) in A. vulgare juveniles. We co-extracted DNA and RNA of 3, 2, 2 and 2 juvenile pools sampled from stages 3 to 6 respectively, using the AllPrep DNA/RNA kit (Qiagen ${ }^{\circledR}$, Venlo, The Netherlands), according to the manufacturer's instructions. We confirmed $w$ VulC presence in each sample by amplifying molecular markers gat $B$ and wsp by PCR (Table S1 for primers and PCR conditions). RNA samples were then treated with DNase $\mathrm{I}\left(4 \mathrm{u}\right.$ at $37^{\circ} \mathrm{C}$ for $1 \mathrm{~h}$ and inactivated at $75^{\circ} \mathrm{C}$ for $10 \mathrm{~min}$, New England Biolabs ${ }^{\circledR}$, Ipswich, MA, USA) and cDNA synthesis was performed using the Superscript SSIII kit (Invitrogen ${ }^{\circledR}$, Carlsbad, CA, USA), according to the manufacturer's instructions, and using $250 \mathrm{ng}$ of RNA (estimated with Nanodrop, Thermo Fisher, Waltham, MA, USA). Then, RT-PCR was performed on all candidate genes (Table S2 for primers and PCR conditions) and PCR products were run on an agarose gel 1.5\%. After staining the gel for $10 \mathrm{~min}$ in an ethidium bromide bath, bands were revealed under UV light. Candidate genes being expressed during at least one host developmental stage were selected for expression quantification.

Wolbachia $w$ VulC gene expression was quantified by quantitative real-time PCR (qRT-PCR) on three successive samplings. The first sampling was composed of 40, 24, 16, 16 and 16 A. vulgare juvenile pools sampled from stages 2 to 6 , respectively. The second sampling was composed of triplicated pools of 10, 10, 9, 6, 6, 6 and 6 A. vulgare juveniles corresponding to stages 1 to 7 , respectively. The third sampling was composed of triplicated pools of eight $C$. convexus juveniles for each stage from 1 to 7 . All quantitative experiments were conducted with two technical replicates, using a LightCycler LC480 device (Roche ${ }^{\circledR}$, Basel, Switzerland). Reactions were made in a total volume of $10 \mu \mathrm{L}$ composed of $1 \times$ Fast SYBR GREEN Master Mix (Roche ${ }^{\circledR}$, Basel, Switzerland), $5 \mu \mathrm{M}$ of each primer, and $2.5 \mu \mathrm{L}$ of $4 \times$-diluted cDNA synthesized as above. Cycle conditions were as described in Le Clec'h et al. [43].

To identify appropriate reference genes, we measured the expression of 15 Wolbachia housekeeping genes (wsp , coxA , atpD , sucB, gatB, gltA, L2, L20, S4, fabF, pyrB, purF, tkt, hcpA and fbpA) by qRT-PCR in $A$. vulgare stages 2 to 6 . We then selected those exhibiting a highly correlated expression $(r>0.95)$ using the BestKeeper software (version 1) [53] (Table S1 for primers and PCR conditions). At last, we verified that the expression of the selected genes remained constant across stages in $A$. vulgare and $C$. convexus relative to the wsp copy number. This procedure resulted in the validation of six genes: gltA, $L 2, L 20, S 4$, fabF and purF. Expression ratios were calculated by combining efficiency and $2^{\Delta \Delta c t}$, according to LightCycler 480 SW v1.5 software manual (Roche ${ }^{\circledR}$, Basel, Switzerland). Efficiency and cycle threshold were assessed by real-time PCR (RT-PCR) Miner [54]. Then, each expression ratio was calibrated against stage 2 (corresponding to the earliest stage for which all genes were amplified in all samplings). Under- and over-expression were considered with thresholds of 0.5 and 2, respectively for all successive samplings.

To compare $w \mathrm{VulC}$ gene expression patterns between $A$. vulgare and C. convexus hosts, we used cross-correlation tests using $\mathrm{R}$ software [55]. This test measures correlation by taking into account gene expression patterns shifted between stages (hence taking into account the one-stage shift of sexual differentiation that occurs between the two hosts [41]). This test was applied after an autocorrelation test aimed at verifying the absence of autocorrelation between the different time steps. In positive cross-correlation tests, we computed the $\eta^{2}$ value to verify that the variance did not influence the cross-correlation test. 


\subsection{Functional Annotation of Candidate Genes}

Function prediction of the final set of candidate genes was performed by searching the following databases: PFAM [56], SMART [57], cdd [58], cog [59], kog [60] and signal peptide [61]. Results were accounted as significant with an e-value $<10^{-4}$.

\subsection{Identification of Candidate Genes in the f Element}

Considering the $f$ element as the Wolbachia nuclear insert characterized by Leclercq et al. [16], the presence of the final set of feminization candidate genes from $w \mathrm{VulC}$ in the $f$ element was investigated using BLASTp against $f$ element sequences sensu Leclercq et al. [16] (GenBank accession numbers LYUU01002088.1-LYUU01002096.1), with a maximal e-value set to 0.001 and at least $90 \%$ of identity.

\section{Results}

\subsection{Sequencing of wCon Wolbachia Genome}

To sequence the $w$ Con Wolbachia genome, we first applied an enrichment method, as Wolbachia DNA is often in low abundance compared to host genetic material (nuclear and mitochondrial). To evaluate which $C$. convexus tissue contains the highest abundance in Wolbachia DNA, we quantified three single-copy genes by means of qPCR (androgenic hormone for nuclear DNA, cytochrome oxidase I for mitochondrial DNA and wsp for Wolbachia DNA) in three different tissues (gonads, hemolymph and nervous cord). The highest level of wCon DNA was found in gonads ( 1 Wolbachia bp for $\sim 330$ nuclear bp), followed by the nervous cord ( 1 Wolbachia bp for $\sim 720$ nuclear bp) and hemolymph ( $\sim 1$ Wolbachia bp for $\sim 34,720$ nuclear bp) (Figure 1A). These figures correspond to 1-4 Wolbachia cells per host cell on average. The quantity of mitochondrial nucleotides was lower than that of Wolbachia ( 1 Wolbachia bp for $\sim 0.4$ mitochondrial bp in ovaries; Figure 1B). Subsequently, we applied our DNA extraction and enrichment protocol to a pool of 30 gonad pairs from $C$. convexus sisters, reaching a $>300$-fold enrichment in wCon DNA (Figure 1C,D).

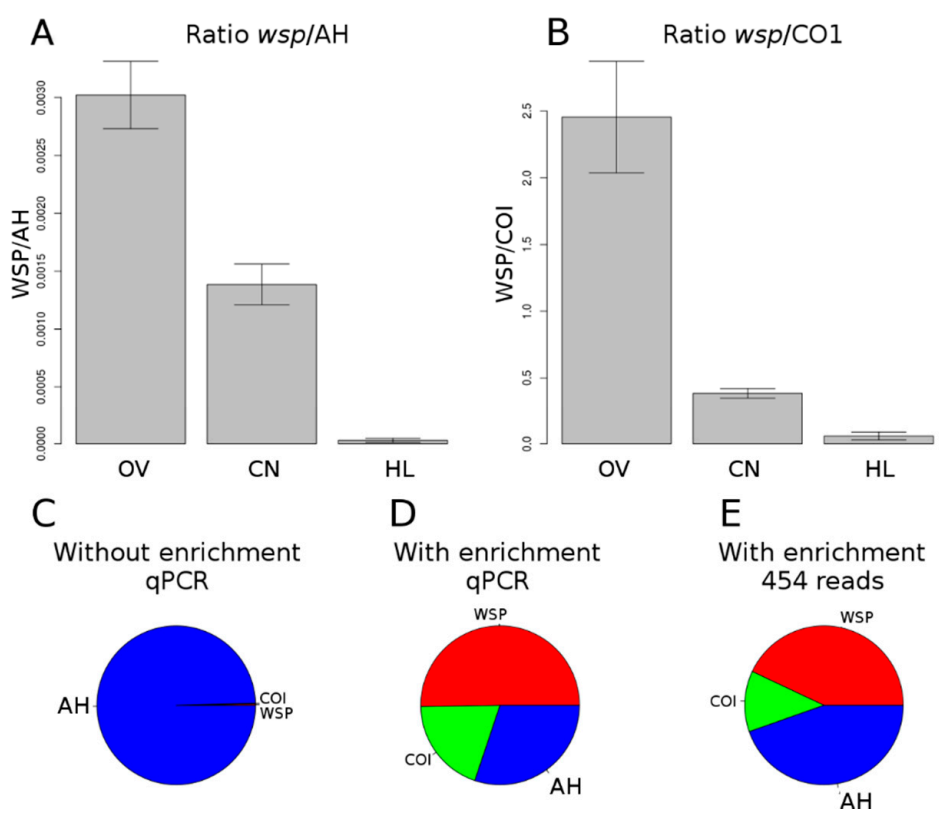

Figure 1. Ratios of wsp gene copy number relative to androgenic hormone (AH) copy number (A) and cytochrome oxidase I (COI) copy number (B), in ovaries (OV), nervous cord (CN) and hemolymph (HL). Proportions of base pairs based of $w$ Con (red), mitochondrial (green) and nuclear genomes (blue) estimated by quantitative PCR (qPCR) without (C) and with (D) enrichment, and by mapping of pyrosequencing reads on assembled genomes (E). WSP: please define. 
Sequencing of this sample generated 395,850 reads representing a total of $110,934,433 \mathrm{bp}$. 16,491 reads were filtered out for low quality and 47,065 reads that mapped against $C$. convexus mitochondrial genome were discarded. In total, 163,099 reads (43\%) were mapped against the final set of $w$ Con contigs. Therefore, qPCR estimation of $w$ Con DNA proportion $(50 \%)$ was close to that obtained by sequencing (Figure 1D,E). From these reads, we assembled the $w$ Con Wolbachia genome in 237 contigs, with a total size of $2.1 \mathrm{Mb}$, an average sequencing depth of $25 \times$, a N50 of $4.5 \mathrm{~kb}$ and a GC content of $34.7 \%$. Contig size ranged from 404 to $71,427 \mathrm{bp}$. PROKKA annotation pipeline revealed the presence of 2359 coding sequences with an average size of 702 bp per gene, 35 transfer RNA (tRNA) and 3 ribosomal RNA (rRNA) genes (Table 1). Genome size is likely overestimated since redundant repeats are present at the ends of contigs resulting from manual scaffolding, as described in Section 2.2. Consistently, assignment of annotated coding DNA sequences (CDS) to COG categories revealed that $w$ Con contains a high number of genes in the category "Replication, Recombination and DNA Repair" among the 7 Wolbachia genomes compared (Figure S2). This COG category includes transposable elements (402 repeats in $w$ Con).

Core genome analysis performed on five complete Wolbachia genomes from arthropods ( $w \mathrm{Mel}$, $w \mathrm{Pip}-\mathrm{Pel}, w \mathrm{Ri}, w \mathrm{Ha}$ and $w \mathrm{No}$ ) revealed the presence of 762 orthologous groups in their core genome. We found 752 and 755 of these orthologous groups in the $w$ Con and $w$ VulC genomes, respectively (748 of which are shared by $w$ Con and $w$ VulC). Furthermore, 35 tRNA and 3 rRNA genes were characterized in both $w$ Con and $w$ VulC genomes (Table 1). Altogether, these analyses indicate that we obtained reliable assemblies of the $w$ Con and $w$ VulC genomes, capturing most of the genetic information despite assembly fragmentation (237 and 10 contigs for $w \mathrm{Con}$ and $w \mathrm{VulC}$, respectively).

\subsection{In Silico Determination of Candidate Genes}

The $w$ VulC Wolbachia genome contains 1888 annotated coding sequences. A succession of in silico filters (see Materials and Methods) allowed us to establish a set of feminization candidate genes. As a result, based on the $w \mathrm{VulC}$ annotation, we excluded all repeats $(n=792)$, pseudogenes $(n=26)$, genes $<150 \mathrm{bp}(n=52)$ and small CDS of genes split in two CDS $(n=16)$. We also removed genes orthologous to the ones identified in the core genome of five Wolbachia strains of arthropods ( $w \mathrm{Mel}$, $w \mathrm{Ri}, w \mathrm{Pip}-\mathrm{Pel}, w \mathrm{Ha}$ and $w \mathrm{No})(n=721)$. This number is different from the above core genome analysis $(n=755)$ because a subset of core genes was discarded as part of previous filters. Next, remaining $w \mathrm{VulC}$ proteins were compared to their homologs in the non-feminizing $w$ Con Wolbachia genome (CI-inducing strain), and those showing 100\% similarity $(n=16)$ were excluded (Table S3, Figure S1). The 265 remaining $w$ VulC genes were considered as a first set of feminization candidate genes and were processed for expression studies. 
Table 1. Wolbachia genome features with $w$ Con and $w$ VulC.

\begin{tabular}{|c|c|c|c|c|c|c|c|c|c|c|}
\hline Supergroup & B & $\mathbf{B}$ & $\mathbf{B}$ & B & $\mathbf{A}$ & $\mathbf{A}$ & $\mathbf{A}$ & $\mathrm{C}$ & $\mathrm{D}$ & $\mathbf{F}$ \\
\hline Strain & $w$ Con & $w$ VulC & $w$ No & $w$ Pip-Pel & $w$ Mel & $w \mathbf{R i}$ & $w \mathrm{Ha}$ & $w \mathrm{Oo}$ & $w \mathrm{Bm}$ & $w \mathrm{Cle}$ \\
\hline Host & $\begin{array}{l}\text { Cylisticus } \\
\text { convexus }\end{array}$ & $\begin{array}{l}\text { Armadillidium } \\
\text { vulgare }\end{array}$ & $\begin{array}{l}\text { Drosophila } \\
\text { simulans }\end{array}$ & $\begin{array}{c}\text { Culex } \\
\text { quinque-fasciatus }\end{array}$ & $\begin{array}{l}\text { Drosophila } \\
\text { melanogaster }\end{array}$ & $\begin{array}{l}\text { Drosophila } \\
\text { simulans }\end{array}$ & $\begin{array}{l}\text { Drosophila } \\
\text { simulans }\end{array}$ & $\begin{array}{c}\text { Onchocerca } \\
\text { ochengi }\end{array}$ & $\begin{array}{l}\text { Brugia } \\
\text { malayi }\end{array}$ & $\begin{array}{c}\text { Cimex } \\
\text { lectularius }\end{array}$ \\
\hline Size (bp) & $2,109,518$ & $1,663,741$ & $1,301,823$ & $1,482,455$ & $1,267,782$ & $1,445,873$ & $1,295,804$ & 957,990 & $1,080,084$ & $1,250,060$ \\
\hline $\mathrm{G}+\mathrm{C} \%$ & 34.69 & 34.49 & 34.50 & 34.60 & 35.46 & 35.40 & 35.34 & 32.10 & 35.20 & 36.30 \\
\hline Coding sequences & 2356 & 1888 & 1040 & 1275 & 1195 & 1150 & 1010 & 842 & 805 & 1216 \\
\hline Coding base density & 0.78 & 0.83 & 0.80 & 0.86 & 0.94 & 0.80 & 0.78 & 0.67 & 0.75 & 0.75 \\
\hline Gene average size & 702 & 725 & 1013 & 951 & 851 & 976 & 1000 & 757 & 899 & 771 \\
\hline rRNA & 3 & 3 & 3 & 3 & 3 & 3 & 3 & 3 & 3 & 3 \\
\hline tRNA & 35 & 35 & 34 & 34 & 34 & 34 & 34 & 34 & 34 & 34 \\
\hline Pseudogenes & NA & 375 & 95 & 110 & 74 & 114 & 93 & 196 & 98 & 109 \\
\hline
\end{tabular}




\subsection{Candidate Gene Expression throughout Host Development}

Among the 265 remaining $w$ VulC genes, successful PCR amplification was obtained for 216 candidate genes. Then, gene expression of the 216 candidate genes from the $w \mathrm{VulC}$ Wolbachia genome was investigated by RT-PCR throughout $A$. vulgare development, in particular during the stages of sexual differentiation, i.e., from stages 3 to 6 . We found that 139 out of $216 w$ VulC genes were expressed during at least at one of these host developmental stages (Table S3). Next, gene expression of the 139 candidate genes was investigated by qRT-PCR throughout developmental stages of the host A. vulgare, using two successive samplings. First, we investigated expression profiles of these genes during host developmental stages 2 to 6, using stage 2 for calibration (see Materials and Methods, Figure S3). This analysis identified 13 and 29 genes that were 2-fold under and over-expressed, respectively, in at least one of stages 3 to 6 . Expression profiles of these 42 differentially expressed genes were then investigated within the frame of a second sampling. The second sampling was designed to confirm and refine expression profiles of $w \mathrm{VulC}$ candidate genes throughout the full development sequence of the host $A$. vulgare (i.e., from stages 1 to 8 ). In total, seven genes were below the 2-fold expression threshold for all replicates. Therefore, 35 genes were consistently under or over-expressed, making them the final set of candidate genes.

Finally, expression profiles of the $35 w \mathrm{VulC}$ candidate genes were investigated, during developmental stages 1 to 7 in the heterologous host $C$. convexus, in which $w \mathrm{VulC}$ transfection was shown to be associated with feminization (Figure 2) [41]. We found that all $35 w \mathrm{VulC}$ genes were expressed during C. convexus development, but only 29 of these genes were significantly down or up-regulated in both hosts (Figure 2, Table S3). A cross-correlation analysis of gene expression profiles between the two hosts indicated that three $w \mathrm{VulC}$ genes exhibited the same gene expression profile throughout the entire developmental sequence in both hosts: wVul_1408 and wVul_1821 with one-stage shift that perfectly matches the one-stage shift of sexual differentiation existing between $A$. vulgare and $C$. convexus (Figure 2) [41], and wVul_0881, but without any stage shift between the two hosts (Figure S4). 

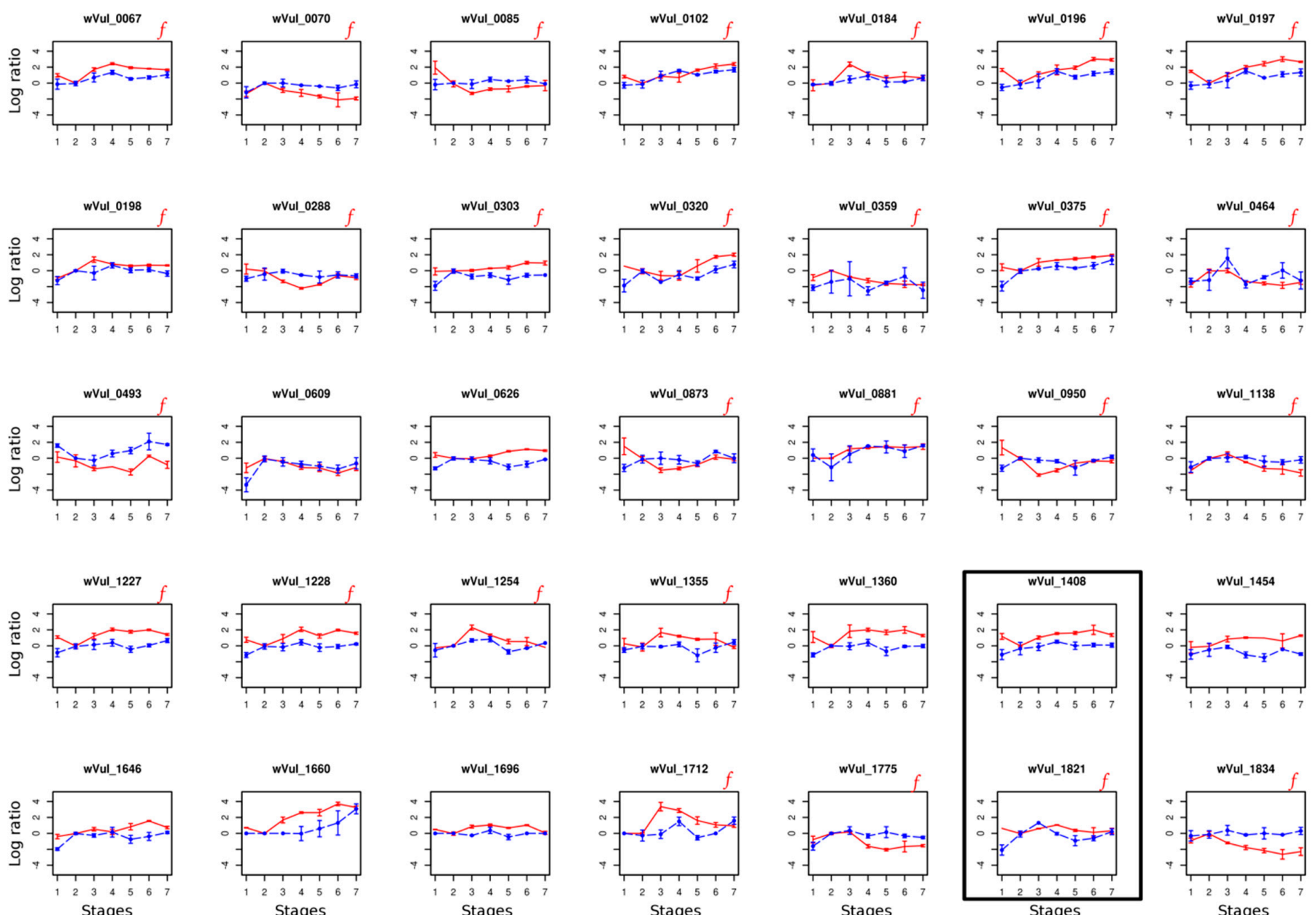

Figure 2. Candidate gene $\log 2$ expression of 35 candidate genes during both homologous and heterologous host development (A. vulgare in red and C. convexus in blue, respectively). All candidate genes are consistently over- or under-expressed during native host development (in $A$. vulgare). All genes present in the $f$ element are labeled with a red " $f$ ". The two genes showing a significant cross-correlation with exactly one-stage shift between the two hosts are boxed. 


\subsection{Prediction of General Function of wVulC Candidate Genes}

We investigated the general function of the $35 w \mathrm{VulC}$ candidate genes that are consistently over or under-expressed throughout $A$. vulgare development. We were able to infer functions for 12 of these genes, in which we found a total of 14 different domains (up to 4 domains per gene) (Table 2; Table S4). We unraveled the following predicted domains associated with:

1. Eukaryotic-like domains involved in protein-protein interactions: ANK (Ankyrin Repeat) $[62,63]$ in wVul_0303, wVul_1408 and wVul_1775; LRR (Leucine Rich Repeat) [64,65] in wVul_0493; TPR (Tetratricopeptide Repeat) [66] in wVul_0881;

2. Cytoskeleton: Hook in wVul_0067 that mediates attachment to microtubules [67]; Spc7 in wVul_0375 that is required for kinetochore-spindle association during cell division [68];

3. DNA binding: Smc (Structural Maintenance of Chromosomes) in wVul_0067,wVul_0085 and wVul_0375 that binds DNA and acts in organization and segregation of chromosomes for partition [69,70]; AAA (ATPases Associated with diverse cellular Activities) [71] in wVul_0375 that are involved in diverse cellular functions including DNA replication, gene expression and also vesicle-mediated transport and peroxisome assembly; p53 interaction protein in wVul_1775 that is responsible for DNA binding [72].

4. Hydrolase function: Lipase class 3 in wVul_0873 that hydrolyses ester linkages of triglycerides [73,74]; Peptidases/proteases that hydrolysepeptidic bounds [75,76] in wVul_1408,wVul_1454 and wVul_1775;

5. Membranes: Mitofilin in wVul_0085 that is an inner membrane protein domain of mitochondria that controls cristae morphology [77,78]; IncA in wVul_1360 that is associated with homotypic fusion of inclusions in the obligate intracellular bacterium Chlamydia trachomatis [79]; OmpA-like superfamily in wVul_0359 that is an outer membran protein domain [80]; Trp in wVul_1408 and wVul_1775 that is a transient-receptor-potential calcium channel protein [81].

Table 2. Functional domains found in the 35 candidate genes. Underlined genes are present in the $f$ element.

\begin{tabular}{|c|c|c|}
\hline Gene Number & Annotation & Brief Description \\
\hline$\underline{67} ; \underline{85} ; \underline{375}$ & Smc & Chromosome Segregation \\
\hline 375 & AAA & DNA breaks \\
\hline$\overline{375}$ & Spc7 & Chromosome Segregation \\
\hline$\underline{67}$ & Hook & $\mathrm{N}$-term binding to microtubules \\
\hline$\underline{85}$ & Mitofilin & Mitochondria inner membrane protein \\
\hline$\overline{359}$ & OMPA-like & Surface \\
\hline$\overline{1360}$ & IncA & Recruitment of lipids \\
\hline $1408 ; \underline{1775}$ & $\operatorname{Trp}$ & Transient receptor channels \\
\hline 493 & LRR & Eukaryotic-like domain \\
\hline$\overline{881}$ & TPR & Eukaryotic-like domain \\
\hline$\underline{303} ; 1408 ; 1775$ & ANK & Eukaryotic-like domain \\
\hline 873 & Lipase & Hydrolizetriglycerides \\
\hline $1408 ; 1454 ; 1775$ & Peptidase/protease & Hydrolise peptide bonds \\
\hline$\underline{1775}$ & p53 & Bind to DNA, eukaryotic-like domain \\
\hline
\end{tabular}

\subsection{Presence of Candidate Genes in the $f$ Element}

We searched the $f$ element sequence for the $35 w \mathrm{VulC}$ candidate genes. Blast results indicated that 27 genes are present in the $f$ element with copy numbers varying from 1 to 5 (Table S5). The $8 w$ VulC candidate genes with no hit in the $f$ element were wVul_0609, wVul_0626, wVul_1360, wVul_1408, wVul_1454,wVul_1646,wVul_1660 and wVul_1696. Among the 27 genes present in both $w$ VulC and the $f$ element, 20 presented identical copies at the amino acid level (Table S5). The lowest amino acid identity was observed for wVul_0198 (95.35\% identity). There was no significant enrichment of differentially expressed genes in the $f$ element (Fisher's Exact test, $p=0.22$ ). 


\section{Discussion}

Our analyses resulted in the identification of a reduced set of 35 candidate genes that may be implicated in Wolbachia $w$ VulC-mediated feminization in the native host $A$. vulgare and the heterologous host $C$. convexus. The vast majority of $w \mathrm{VulC}$ genes that we tested are consistently expressed throughout the entire host development sequence, as previously observed for Wolbachia w $\mathrm{Mel}$ in its host Drosophila melanogaster [82]. Only one-fourth of genes analyzed by qRT-PCR $(35 / 139)$ are expressed differentially, of which only one-third are functionally annotated (12/35). For example, we noted the presence of several eukaryotic-like domain proteins (ANK, TPR and LRR) and an outer membrane protein (OmpA-like) in our set of candidate genes. Identifying genes encoding such domains among our candidates is not really surprising, as previous host/Wolbachia molecular interaction studies have often searched for such functional domains when using targeted strategies to identify candidate genes [27-29]. One advantage of the strategy we used here was the ability to identify candidate genes without any a priori knowledge of their function. This allowed us to identify functionally annotated candidate genes among the "usual suspects", as well as candidate genes for which no functional information is available. Genes from the latter category may be prime choices for future functional studies, in the context of feminization induced by $w$ VulC. This point may be relevant in identifying Wolbachia effectors, as exemplified by cifA and cifB, and their homologs $c i d A$ and $\operatorname{cidB}$, which were not functionally annotated before their identification as CI-effectors in $w \mathrm{Mel}$ and $w$ Pip-Pel strains, respectively [35,36].

The candidate gene approach we used also has its own potential limitations. First, as it largely relies on gene expression patterns, we implicitly assumed that gene expression and protein expression are correlated, which may not necessarily be true. This assumption is, however, generally made by studies involving gene expression. Second, we opted to discard core genes and mobile genetic elements. In particular, the rationale for removing mobile genetic elements was their repeated nature that makes them poorly suited to the design of specific PCR assays. Nevertheless, it is clear that genes encoded by mobile genetic elements may be involved in host-Wolbachia interactions, as perfectly exemplified by the cifA and cifB genes that are located in prophage WO [35,36]. However, our strategy did not dismiss those genes as candidate genes. Instead, we opted to give them lower priority in our expression analyses. Third, our approach is based on gene expression profiling throughout host development. However, during host development, Wolbachia is likely involved in various biological processes unrelated to feminization. For example, while host cells are dividing, Wolbachia cell population is also in expansion, replicating fast and colonizing new cells [83-88]. Therefore, a subset of our candidate genes may have passed our successive filters not because they are involved in feminization but because they are involved in a confounding biological process taking place during host sexual development.

In this context, the three domains Smc, Hook and Spc7 found in the wVul_0067, wVul_0085 and wVul_0375 candidate genes, are consistent with the involvement of these candidate genes in cell division [67-70]. Moreover, Wolbachia cell multiplication requires lipid recruitment to generate new membranes and additional nutrient supply. Thus, it is conceivable that the wVul_1360 candidate gene containing an IncA domain may contribute to lipid recruitment, as it seems to act in C. trachomatis $[79,89,90]$. This may also explain the presence of several lipase or peptidase domains among our candidate genes, which may contribute to additional nutrient supply. Interestingly, two candidate genes (wVul_1408 and wVul_1775) possess both a eukaryotic-like domain (ANK) and a peptidase/protease domain, suggesting that Wolbachia might cleave host peptides.

Among the 35 feminization candidate genes we identified, 27 were also found in the $f$ element, which is a piece of a feminizing Wolbachia genome horizontally transferred in the nuclear genome of A. vulgare and involved in female sex determination [16]. Assuming that the molecular genetic basis of feminization by Wolbachia and the $f$ element is the same, the 27 aforementioned genes are candidates for acting as master sex determination genes in the A. vulgare genome. However, in spite of the high nucleotide similarity of these genes in $w$ VulC and the $f$ element, their function or regulation may not necessarily be conserved in the two genetic entities. This may be the case especially when considering 
that Wolbachia genes are located in the cytoplasm and controlled in a prokaryotic context while $f$ element genes are located in the nucleus and controlled in a eukaryotic context. Furthermore, feminization induced by Wolbachia and the $f$ element presents differences (reviewed in [15]). For example, it is possible to experimentally masculinize young females carrying the $f$ element by grafting of androgenic glands [91]. By contrast, young females infected by Wolbachia are not masculinized using the same experimental procedure [92,93]. Thus, the underlying mechanisms of feminization by the $f$ element and Wolbachia may differ, at least partly. Nevertheless, given that the $f$ element is derived from Wolbachia, it is parsimonious to consider that the molecular genetic basis for feminization shows at least some overlap between the two feminizers. For this reason, it is relevant to consider the 27 Wolbachia feminization candidate genes present in the $f$ element as candidate genes for master sex determination in females carrying the $f$ element. In this context, it will be useful to investigate the expression profiles of these candidate genes during sexual development of $A$. vulgare females carrying the $f$ element.

In conclusion, we identified a set of 35 Wolbachia $w$ VulC genes that may be involved in the induction of cytoplasmic sex determination in the terrestrial isopod A. vulgare. Our results open the avenue for further functional analyses of these candidate genes, which may provide additional insights into the molecular genetic basis and cellular mechanisms of feminization. Of the 35 genes, 2 genes ( $w$ Vul_1408 and $w$ Vul_1821) presented an expression profile in the heterologous host C. convexus which is correlated with that in the natural host $A$. vulgare and showing a one-stage shift corresponding to the one-stage shift existing in the sexual development sequence of $A$. vulgare and $C$. convexus. While $w$ Vul_1821 contains no known functional domain, $w$ Vul_1408 contains two known functional domains, including an Ankyrin Repeat Domain and a protease domain. Although $w$ Vul_1408 is absent from the $f$ element, it nevertheless constitutes a prime candidate for being involved in Wolbachia $w$ VulC-mediated feminization. While $w$ Vul_1408 may constitute a top candidate in subsequent studies aiming at unraveling the molecular genetic basis of feminization, it may also be important to invest efforts in the identification of the function of other candidate genes such as $w$ Vul_1821. This will ultimately allow us to better understand the impact of Wolbachia endosymbionts on the mechanisms of sex determination of their terrestrial isopod hosts. It will also shed new light on the role of Wolbachia in sex chromosome turnovers experienced by A. vulgare in particular [16], and terrestrial isopods in general [94].

Supplementary Materials: The following are available online at http:/ /www.mdpi.com/2073-4425/9/6/290/s1. Figure S1: Circular DNA plot of the $w$ VulC genome; Figure S2: Distribution of COG families; Figure S3: Heatmap of the logratio of $139 w$ VulC gene expression during A. vulgare developmental stages; Figure S4: Cross-correlation values of 35 candidate genes from Wolbachia wVulC; Table S1: Primers and PCR conditions; Table S2: Primers and PCR conditions of candidate genes; Table S3: Categorization of 1888 wVulC genes; Table S4: Functional annotation of 35 candidate genes; Table S5: BLAST output of $w$ VulC candidate genes in the $f$ element.

Author Contributions: M.B., P.G. and R.C. conceived and designed the experiments; M.B. and I.G. performed the experiments; M.B. and B.M. analyzed the data; P.G. and R.C. contributed reagents/materials/analysis tools; M.B., P.G. and R.C. wrote the paper.

Funding: This work was funded by European Research Council Starting grant 260729 (EndoSexDet) and Agence Nationale de la Recherche grant ANR-15-CE32-0006-01 (CytoSexDet) to R.C., the 2015-2020 State-Region Planning Contracts (CPER) and European Regional Development Fund (FEDER), and intramural funds from the Centre National de la Recherche Scientifique and the University of Poitiers.

Acknowledgments: We thank Catherine Debenest, Carine Delaunay, Alexandra Lafitte, Jérôme Lesobre and Maryline Raimond for technical advice and assistance during the course of the project.

Conflicts of Interest: The authors declare no conflict of interest.

\section{References}

1. Bachtrog, D.; Mank, J.E.; Peichel, C.L.; Kirkpatrick, M.; Otto, S.P.; Ashman, T.-L.; Hahn, M.W.; Kitano, J.; Mayrose, I.; Ming, R.; et al. Sex determination: Why so many ways of doing it? PLoS Biol. 2014, 12, e1001899. [CrossRef] [PubMed]

2. Schwanz, L.E. The evolution of sex determination by Leo W. Beukeboom and Nicolas Perrin. Q. Rev. Biol. 2015, 90, 333-334. [CrossRef] 
3. Cordaux, R.; Bouchon, D.; Grève, P. The impact of endosymbionts on the evolution of host sex-determination mechanisms. Trends Genet. 2011, 27, 332-341. [CrossRef] [PubMed]

4. Rigaud, T. Inherited microorganisms and sex determination of arthropod hosts. In Influential Passengers: Inherited Microorganisms and Arthropod Reproduction; O'Neill, S.L., Hoffmann, A.A., Werren, J.H., Eds.; Oxford University Press: Oxford, UK, 1997; pp. 81-101.

5. Jahnke, M.; Smith, J.E.; Dubuffet, A.; Dunn, A.M. Effects of feminizing microsporidia on the masculinizing function of the androgenic gland in Gammarus duebeni. J. Invertebr. Pathol. 2013, 112, 146-151. [CrossRef] [PubMed]

6. Werren, J.H.; Baldo, L.; Clark, M.E. Wolbachia: Master manipulators of invertebrate biology. Nat. Rev. Microbiol. 2008, 6, 741-751. [CrossRef] [PubMed]

7. Zug, R.; Hammerstein, P. Still a host of hosts for Wolbachia: Analysis of recent data suggests that $40 \%$ of terrestrial arthropod species are infected. PLoS ONE 2012, 7, e38544. [CrossRef] [PubMed]

8. Bouchon, D.; Cordaux, R.; Grève, P. Feminizing Wolbachia and the evolution of sex determination in isopods. In Insect Symbiosis; Bourtzis, K., Miller, T., Eds.; Taylor and Francis Group LLC: Boca Raton, FL, USA, 2008; Volume 3, pp. 273-294.

9. Hiroki, M.; Kato, Y.; Kamito, T.; Miura, K. Feminization of genetic males by a symbiotic bacterium in a butterfly, Eurema hecabe (Lepidoptera: Pieridae). Naturwissenschaften 2002, 89, 167-170. [CrossRef] [PubMed]

10. Negri, I.; Pellecchia, M.; Mazzoglio, P.J.; Patetta, A.; Alma, A. Feminizing Wolbachia in Zyginidia pullula (Insecta, Hemiptera), a leafhopper with an XX/X0 sex-determination system. Proc. Biol. Sci. 2006, 273, 2409-2416. [CrossRef] [PubMed]

11. Cordaux, R.; Michel-Salzat, A.; Frelon-Raimond, M.; Rigaud, T.; Bouchon, D. Evidence for a new feminizing Wolbachia strain in the isopod Armadillidium vulgare: Evolutionary implications. Heredity 2004, 93, 78-84. [CrossRef] [PubMed]

12. Martin, G.; Juchault, P.; Legrand, J.-J. Mise en évidence d'un micro-organisme intracytoplasmique symbiote de l'oniscoïde Armadillidium vulgare latr. dont la présence accompagne l'intersexualité ou la féminisation totale des mâles génétiques de la lignée thélygène. CR Acad Sci Paris Ser. D 1973, 276, 2313-2316. (In French)

13. Rigaud, T.; Juchault, P.; Mocquard, J.P. Experimental study of temperature effects on the sex ratio of broods in Terrestrial Crustacea Armadillidium vulgare Latr. Possible implications in natural populations. J. Evol. Biol. 1991, 4, 603-617. [CrossRef]

14. Juchault, P.; Legrand, J.-J. Croisement de néo-mâles experimentaux chez Armadillidium vulgare Latr. (Crustace, Isopode, Oniscoide). Mise en evidence d'une hétérogamétie femelle. CR Acad Sci Paris Ser. D 1972, 274, 1387-1389. (In French)

15. Cordaux, R.; Gilbert, C. Evolutionary significance of Wolbachia-to-animal horizontal gene transfer: Female sex determination and the $\mathrm{f}$ element in the isopod Armadillidium vulgare. Genes 2017, 8, 186. [CrossRef] [PubMed]

16. Leclercq, S.; Thézé, J.; Chebbi, M.A.; Giraud, I.; Moumen, B.; Ernenwein, L.; Grève, P.; Gilbert, C.; Cordaux, R. Birth of a W sex chromosome by horizontal transfer of Wolbachia bacterial symbiont genome. Proc. Natl. Acad. Sci. USA 2016, 113, 15036-15041. [CrossRef] [PubMed]

17. Bhattacharya, T.; Newton, I.L. Mi Casa es Su Casa: How an intracellular symbiont manipulates host biology. Environ. Microbiol. 2017. [CrossRef] [PubMed]

18. Al-Khodor, S.; Al-Quadan, T.; Abu Kwaik, Y. Temporal and differential regulation of expression of the eukaryotic-like ankyrin effectors of Legionella pneumophila. Environ. Microbiol. Rep. 2010, 2, 677-684. [CrossRef] [PubMed]

19. Gavotte, L.; Henri, H.; Stouthamer, R.; Charif, D.; Charlat, S.; Boulétreau, M.; Vavre, F. A Survey of the bacteriophage WO in the endosymbiotic bacteria Wolbachia. Mol. Biol. Evol. 2007, 24, 427-435. [CrossRef] [PubMed]

20. Kent, B.N.; Bordenstein, S.R. Phage WO of Wolbachia: Lambda of the endosymbiont world. Trends Microbiol. 2010, 18, 173-181. [CrossRef] [PubMed]

21. Bordenstein, S.R.; Bordenstein, S.R. Eukaryotic association module in phage WO genomes from Wolbachia. Nat. Commun. 2016, 7, 13155. [CrossRef] [PubMed]

22. Pan, X.; Lührmann, A.; Satoh, A.; Laskowski-Arce, M.A.; Roy, C.R. Ankyrin repeat proteins comprise a diverse family of bacterial type IV effectors. Science 2008, 320, 1651-1654. [CrossRef] [PubMed] 
23. Richards, A.M.; Von Dwingelo, J.E.; Price, C.T.; Abu Kwaik, Y. Cellular microbiology and molecular ecology of Legionella-amoeba interaction. Virulence 2013, 4, 307-314. [CrossRef] [PubMed]

24. Lührmann, A.; Nogueira, C.V.; Carey, K.L.; Roy, C.R. Inhibition of pathogen-induced apoptosis by a Coxiella burnetii type IV effector protein. Proc. Natl. Acad. Sci. USA 2010, 107, 18997-19001. [CrossRef] [PubMed]

25. Rikihisa, Y.; Lin, M. Anaplasma phagocytophilum and Ehrlichia chaffeensis type IV secretion and ANK proteins. Curr. Opin. Microbiol. 2010, 13, 59-66. [CrossRef] [PubMed]

26. Papafotiou, G.; Oehler, S.; Savakis, C.; Bourtzis, K. Regulation of Wolbachia ankyrin domain encoding genes in Drosophila gonads. Res. Microbiol. 2011, 162, 764-772. [CrossRef] [PubMed]

27. Duron, O.; Boureux, A.; Echaubard, P.; Berthomieu, A.; Berticat, C.; Fort, P.; Weill, M. Variability and expression of ankyrin domain genes in Wolbachia variants infecting the mosquito Culex pipiens. J. Bacteriol. 2007, 189, 4442-4448. [CrossRef] [PubMed]

28. Sinkins, S.P.; Walker, T.; Lynd, A.R.; Steven, A.R.; Makepeace, B.L.; Godfray, H.C.J.; Parkhill, J. Wolbachia variability and host effects on crossing type in Culex mosquitoes. Nature 2005, 436, 257-260. [CrossRef] [PubMed]

29. Walker, T.; Klasson, L.; Sebaihia, M.; Sanders, M.J.; Thomson, N.R.; Parkhill, J.; Sinkins, S.P. Ankyrin repeat domain-encoding genes in the wPip strain of Wolbachia from the Culex pipiens group. BMC Biol. 2007, 5, 39. [CrossRef] [PubMed]

30. Pichon, S.; Bouchon, D.; Liu, C.; Chen, L.; Garrett, R.A.; Grève, P. The expression of one ankyrin PK2 allele of the WO prophage is correlated with the Wolbachia feminizing effect in isopods. BMC Microbiol. 2012, 12, 55. [CrossRef] [PubMed]

31. Pichon, S.; Bouchon, D.; Cordaux, R.; Chen, L.; Garrett, R.A.; Grève, P. Conservation of the Type IV secretion system throughout Wolbachia evolution. Biochem. Biophys. Res. Commun. 2009, 385, 557-562. [CrossRef] [PubMed]

32. Wu, M.; Sun, L.V.; Vamathevan, J.; Riegler, M.; Deboy, R.; Brownlie, J.C.; McGraw, E.A.; Martin, W.; Esser, C.; Ahmadinejad, N.; et al. Phylogenomics of the reproductive parasite Wolbachia pipientis wMel: A streamlined genome overrun by mobile genetic elements. PLoS Biol. 2004, 2, e69. [CrossRef] [PubMed]

33. Foster, J.; Ganatra, M.; Kamal, I.; Ware, J.; Makarova, K.; Ivanova, N.; Bhattacharyya, A.; Kapatral, V.; Kumar, S.; Posfai, J.; et al. The Wolbachia genome of Brugia malayi: Endosymbiont evolution within a human pathogenic nematode. PLoS Biol. 2005, 3. [CrossRef] [PubMed]

34. Félix, C.; Pichon, S.; Braquart-Varnier, C.; Braig, H.; Chen, L.; Garrett, R.A.; Martin, G.; Grève, P. Characterization and transcriptional analysis of two gene clusters for type IV secretion machinery in Wolbachia of Armadillidium vulgare. Res. Microbiol. 2008, 159, 481-485. [CrossRef] [PubMed]

35. Beckmann, J.F.; Ronau, J.A.; Hochstrasser, M. A Wolbachia deubiquitylating enzyme induces cytoplasmic incompatibility. Nat. Microbiol. 2017, 2, 17007. [CrossRef] [PubMed]

36. LePage, D.P.; Metcalf, J.A.; Bordenstein, S.R.; On, J.; Perlmutter, J.I.; Shropshire, J.D.; Layton, E.M.; Funkhouser-Jones, L.J.; Beckmann, J.F.; Bordenstein, S.R. Prophage WO genes recapitulate and enhance Wolbachia-induced cytoplasmic incompatibility. Nature 2017, 543, 243-247. [CrossRef] [PubMed]

37. Bonneau, M.; Atyame, C.; Beji, M.; Justy, F.; Cohen-Gonsaud, M.; Sicard, M.; Weill, M. Culex pipiens crossing type diversity is governed by an amplified and polymorphic operon of Wolbachia. Nat. Commun. 2018, 9, 319. [CrossRef] [PubMed]

38. Rice, D.W.; Sheehan, K.B.; Newton, I.L.G. Large-Scale Identification of Wolbachia pipientis Effectors. Genome Biol. Evol. 2017, 9, 1925-1937. [CrossRef] [PubMed]

39. Moret, Y.; Juchault, P.; Rigaud, T. Wolbachia endosymbiont responsible for cytoplasmic incompatibility in a terrestrial crustacean: Effects in natural and foreign hosts. Heredity 2001, 86, 325-332. [CrossRef] [PubMed]

40. Cordaux, R.; Pichon, S.; Hatira, H.B.A.; Doublet, V.; Grève, P.; Marcadé, I.; Braquart-Varnier, C.; Souty-Grosset, C.; Charfi-Cheikhrouha, F.; Bouchon, D. Widespread Wolbachia infection in terrestrial isopods and other crustaceans. ZooKeys 2012, 123-131. [CrossRef] [PubMed]

41. Badawi, M.; Grève, P.; Cordaux, R. Feminization of the isopod Cylisticus convexus after transinfection of the wVulC Wolbachia Strain of Armadillidium vulgare. PLoS ONE 2015, 10, e128660. [CrossRef] [PubMed]

42. Bouchon, D.; Rigaud, T.; Juchault, P. Evidence for widespread Wolbachia infection in isopod crustaceans: Molecular identification and host feminization. Proc. Biol. Sci. 1998, 265, 1081-1090. [CrossRef] [PubMed]

43. Le Clec'h, W.; Braquart-Varnier, C.; Raimond, M.; Ferdy, J.-B.; Bouchon, D.; Sicard, M. High virulence of Wolbachia after host switching: When autophagy hurts. PLoS Pathog. 2012, 8, e1002844. [CrossRef] [PubMed] 
44. Chandler, C.H.; Badawi, M.; Moumen, B.; Grève, P.; Cordaux, R. Multiple Conserved Heteroplasmic Sites in tRNA genes in the mitochondrial genomes of terrestrial isopods (Oniscidea). Genes Genomes Genet. 2015, 5, 1317-1322. [CrossRef] [PubMed]

45. Darling, A.E.; Mau, B.; Perna, N.T. progressiveMauve: Multiple genome alignment with gene gain, loss and rearrangement. PLoS ONE 2010, 5, e11147. [CrossRef] [PubMed]

46. Husemann, P.; Stoye, J. r2cat: Synteny plots and comparative assembly. Bioinformatics 2010, 26, 570-571. [CrossRef] [PubMed]

47. Kent, W.J. BLAT-The BLAST-like alignment tool. Genome Res. 2002, 12, 656-664. [CrossRef] [PubMed]

48. Seemann, T. PROKKA: Rapid prokaryotic genome annotation. Bioinformatics 2014, 30, 2068-2069. [CrossRef] [PubMed]

49. Li, L.; Stoeckert, C.J.; Roos, D.S. OrthoMCL: Identification of ortholog groups for eukaryotic genomes. Genome Res. 2003, 13, 2178-2189. [CrossRef] [PubMed]

50. Suzuki, S. Androgenic Gland Hormone Is a Sex-Reversing Factor but Cannot Be a Sex-Determining Factor in the Female Crustacean Isopods Armadillidium vulgare. Gen. Comp. Endocrinol. 1999, 115, 370-378. [CrossRef] [PubMed]

51. Suzuki, S.; Yamasaki, K. Sexual bipotentiality of developing ovaries in the terrestrial isopod Armadillidium vulgare (Malacostraca, Crustacea). Gen. Comp. Endocrinol. 1997, 107, 136-146. [CrossRef] [PubMed]

52. Suzuki, S.; Yamasaki, K. Sex reversal by implantations of ethanol-treated androgenic glands of female isopods, Armadillidium vulgare (Malacostraca, Crustacea). Gen. Comp. Endocrinol. 1998, 111, 367-375. [CrossRef] [PubMed]

53. Pfaffl, M.W.; Tichopad, A.; Prgomet, C.; Neuvians, T.P. Determination of stable housekeeping genes, differentially regulated target genes and sample integrity: BestKeeper-Excel-based tool using pair-wise correlations. Biotechnol. Lett. 2004, 26, 509-515. [CrossRef] [PubMed]

54. Zhao, S.; Fernald, R.D. Comprehensive algorithm for quantitative real-time polymerase chain reaction. J. Comput. Biol. 2005, 12, 1047-1064. [CrossRef] [PubMed]

55. R Development CORE TEAM. R: A Language and Environment for Statistical Computing; R Foundation for Statistical Computing: Vienna, Austria, 2008.

56. Finn, R.D.; Bateman, A.; Clements, J.; Coggill, P.; Eberhardt, R.Y.; Eddy, S.R.; Heger, A.; Hetherington, K.; Holm, L.; Mistry, J.; et al. Pfam: The protein families database. Nucleic Acids Res. 2014, 42, D222-D230. [CrossRef] [PubMed]

57. Letunic, I.; Doerks, T.; Bork, P. SMART 7: Recent updates to the protein domain annotation resource. Nucleic Acids Res. 2012, 40, D302-D305. [CrossRef] [PubMed]

58. Marchler-Bauer, A.; Zheng, C.; Chitsaz, F.; Derbyshire, M.K.; Geer, L.Y.; Geer, R.C.; Gonzales, N.R.; Gwadz, M.; Hurwitz, D.I.; Lanczycki, C.J.; et al. CDD: Conserved domains and protein three-dimensional structure. Nucleic Acids Res. 2013, 41, D348-D352. [CrossRef] [PubMed]

59. Tatusov, R.L.; Galperin, M.Y.; Natale, D.A.; Koonin, E.V. The COG database: A tool for genome-scale analysis of protein functions and evolution. Nucleic Acids Res. 2000, 28, 33-36. [CrossRef] [PubMed]

60. Tatusov, R.L.; Fedorova, N.D.; Jackson, J.D.; Jacobs, A.R.; Kiryutin, B.; Koonin, E.V.; Krylov, D.M.; Mazumder, R.; Mekhedov, S.L.; Nikolskaya, A.N.; et al. The COG database: An updated version includes eukaryotes. BMC Bioinform. 2003, 4, 41. [CrossRef] [PubMed]

61. Petersen, T.N.; Brunak, S.; von Heijne, G.; Nielsen, H. SignalP 4.0: Discriminating signal peptides from transmembrane regions. Nat. Methods 2011, 8, 785-786. [CrossRef] [PubMed]

62. Rubtsov, A.M.; Lopina, O.D. Ankyrins. FEBS Lett. 2000, 482, 1-5. [CrossRef]

63. Mosavi, L.K.; Cammett, T.J.; Desrosiers, D.C.; Peng, Z.-Y. The ankyrin repeat as molecular architecture for protein recognition. Protein Sci. 2004, 13, 1435-1448. [CrossRef] [PubMed]

64. Kajava, A.V. Structural diversity of leucine-rich repeat proteins. J. Mol. Biol. 1998, 277, 519-527. [CrossRef] [PubMed]

65. Kobe, B.; Kajava, A.V. The leucine-rich repeat as a protein recognition motif. Curr. Opin. Struct. Biol. 2001, 11, 725-732. [CrossRef]

66. Blatch, G.L.; Lässle, M. The tetratricopeptide repeat: A structural motif mediating protein-protein interactions. BioEssays 1999, 21, 932-939. [CrossRef]

67. Walenta, J.H.; Didier, A.J.; Liu, X.; Krämer, H. The Golgi-Associated hook3 protein is a member of a novel family of microtubule-binding proteins. J. Cell Biol. 2001, 152, 923-934. [CrossRef] [PubMed] 
68. Kerres, A.; Vietmeier-Decker, C.; Ortiz, J.; Karig, I.; Beuter, C.; Hegemann, J.; Lechner, J.; Fleig, U. The fission yeast kinetochore component Spc7 associates with the EB1 family member Mal3 and is required for kinetochore-spindle association. Mol. Biol. Cell 2004, 15, 5255-5267. [CrossRef] [PubMed]

69. Hirano, M.; Hirano, T. Hinge-mediated dimerization of SMC protein is essential for its dynamic interaction with DNA. EMBO J. 2002, 21, 5733-5744. [CrossRef] [PubMed]

70. Jensen, R.B.; Shapiro, L. Cell-cycle-regulated expression and subcellular localization of the Caulobacter crescentus SMC Chromosome Structural Protein. J. Bacteriol. 2003, 185, 3068-3075. [CrossRef] [PubMed]

71. Yu, R.C.; Hanson, P.I.; Jahn, R.; Brünger, A.T. Structure of the ATP-dependent oligomerization domain of N-ethylmaleimide sensitive factor complexed with ATP. Nat. Struct. Biol. 1998, 5, 803-811. [CrossRef] [PubMed]

72. Gorina, S.; Pavletich, N.P. Structure of the p53 tumor suppressor bound to the ankyrin and SH3 domains of 53BP2. Science 1996, 274, 1001-1005. [CrossRef] [PubMed]

73. Anthonsen, H.W.; Baptista, A.; Drabløs, F.; Martel, P.; Petersen, S.B.; Sebastião, M.; Vaz, L. Lipases and esterases: A review of their sequences, structure and evolution. Biotechnol. Annu. Rev. 1995, 1, 315-371. [PubMed]

74. Wong, H.; Schotz, M.C. The lipase gene family. J. Lipid Res. 2002, 43, 993-999. [CrossRef] [PubMed]

75. Nocek, B.P.; Gillner, D.M.; Fan, Y.; Holz, R.C.; Joachimiak, A. Structural basis for catalysis by the mono and dimetalated forms of the dapE-encoded N-succinyl-L,L-diaminopimelic acid desuccinylase. J. Mol. Biol. 2010, 397, 617-626. [CrossRef] [PubMed]

76. Rowsell, S.; Pauptit, R.A.; Tucker, A.D.; Melton, R.G.; Blow, D.M.; Brick, P. Crystal structure of carboxypeptidase G2, a bacterial enzyme with applications in cancer therapy. Structure 1997, 5, 337-347. [CrossRef]

77. John, G.B.; Shang, Y.; Li, L.; Renken, C.; Mannella, C.A.; Selker, J.M.L.; Rangell, L.; Bennett, M.J.; Zha, J. The mitochondrial inner membrane protein mitofilin controls cristae morphology. Mol. Biol. Cell 2005, 16, 1543-1554. [CrossRef] [PubMed]

78. Odgren, P.R.; Toukatly, G.; Bangs, P.L.; Gilmore, R.; Fey, E.G. Molecular characterization of mitofilin (HMP), a mitochondria-associated protein with predicted coiled coil and intermembrane space targeting domains. J. Cell Sci. 1996, 109 Pt 9, 2253-2264. [PubMed]

79. Fields, K.A.; Fischer, E.; Hackstadt, T. Inhibition of fusion of Chlamydia trachomatis inclusions at 32 degrees C correlates with restricted export of IncA. Infect. Immun. 2002, 70, 3816-3823. [CrossRef] [PubMed]

80. Pautsch, A.; Schulz, G.E. Structure of the outer membrane protein a transmembrane domain. Nat. Struct. Biol. 1998, 5, 1013-1017. [CrossRef] [PubMed]

81. Islam, M.S. (Ed.) Transient Receptor Potential Channels; Springer: Dordrecht, The Netherlands, 2011; ISBN 978-94-007-0264-6.

82. Gutzwiller, F.; Carmo, C.R.; Miller, D.E.; Rice, D.W.; Newton, I.L.G.; Hawley, R.S.; Teixeira, L.; Bergman, C.M. Dynamics of Wolbachia pipientis gene expression across the Drosophila melanogaster life cycle. Genes Genomes Genet. 2015, 5, 2843-2856. [CrossRef] [PubMed]

83. Dossi, F.C.A.; da Silva, E.P.; Cônsoli, F.L. Population dynamics and growth rates of endosymbionts during Diaphorina citri (Hemiptera, Liviidae) ontogeny. Microb. Ecol. 2014, 68, 881-889. [CrossRef] [PubMed]

84. Fast, E.M.; Toomey, M.E.; Panaram, K.; Desjardins, D.; Kolaczyk, E.D.; Frydman, H.M. Wolbachia enhance Drosophila stem cell proliferation and target the germline stem cell niche. Science 2011, 334, 990-992. [CrossRef] [PubMed]

85. Fenn, K.; Blaxter, M. Quantification of Wolbachia bacteria in Brugia malayi through the nematode lifecycle. Mol. Biochem. Parasitol. 2004, 137, 361-364. [CrossRef] [PubMed]

86. Landmann, F.; Foster, J.M.; Slatko, B.; Sullivan, W. Asymmetric Wolbachia segregation during early Brugia malayi embryogenesis determines its distribution in adult host tissues. PLoS Negl. Trop. Dis. 2010, 4, e758. [CrossRef] [PubMed]

87. Landmann, F.; Bain, O.; Martin, C.; Uni, S.; Taylor, M.J.; Sullivan, W. Both asymmetric mitotic segregation and cell-to-cell invasion are required for stable germline transmission of Wolbachia in filarial nematodes. Biol. Open 2012, 1, 536-547. [CrossRef] [PubMed]

88. Landmann, F.; Foster, J.M.; Michalski, M.L.; Slatko, B.E.; Sullivan, W. Co-evolution between an endosymbiont and its nematode host: Wolbachia asymmetric posterior localization and AP polarity establishment. PLoS Negl. Trop. Dis. 2014, 8, e3096. [CrossRef] [PubMed] 
89. Creasey, E.A.; Isberg, R.R. Maintenance of vacuole integrity by bacterial pathogens. Curr. Opin. Microbiol. 2014, 17, 46-52. [CrossRef] [PubMed]

90. Kumar, Y.; Valdivia, R.H. Leading a sheltered life: Intracellular pathogens and maintenance of vacuolar compartments. Cell Host Microbe 2009, 5, 593-601. [CrossRef] [PubMed]

91. Juchault, P.; Legrand, J.-J. Modification de la sex ratio dans les croisements entre différentes populations du crustacé oniscoïde Armadllidium vulgare Latr. Notion de déterminisme polygénique et épigénétique du sexe. Arch. Zool. Exp. Gen. 1976, 1117, 81-93. (In French)

92. Juchault, P.; Legrand, J.-J.; Martin, G. Action interspécifique du facteur épigénétique féminisant responsable de la thélygénie et de l'intersexualité du crustacé Armadillididium vulgare (Isopode Oniscoïde). Ann. Embryol. Morphog. 1974, 7, 265-276. (In French)

93. Juchault, P.; Legrand, J.-J. Nature et action interspécifique du facteur épigénétique féminisant responsable d'une perturbation totale ou partielle de l'équilibre endocrinien contrôlant le phénotype sexuel du crustacé Armadillidium vulgare (Isopode Oniscoïde). Ann. Endocrinol. 1974, 35, 387-392. (In French)

94. Becking, T.; Giraud, I.; Raimond, M.; Moumen, B.; Chandler, C.; Cordaux, R.; Gilbert, C. Diversity and evolution of sex determination systems in terrestrial isopods. Sci. Rep. 2017, 7, 1084. [CrossRef] [PubMed]

(C) 2018 by the authors. Licensee MDPI, Basel, Switzerland. This article is an open access article distributed under the terms and conditions of the Creative Commons Attribution (CC BY) license (http://creativecommons.org/licenses/by/4.0/). 